\title{
Integrated Management of Sudden Wilt in Melons, Caused by Monosporascus cannonballus, Using Grafting and Reduced Rates of Methyl Bromide
}

\author{
M. Edelstein, R. Cohen, Y. Burger, and S. Shriber, Department of Vegetable Crops, A.R.O., Newe Ya'ar \\ Research Center, P.O.B. 1021, Ramat Yishay 30095 Israel; S. Pivonia, 'Arava Research and Development, Sapir \\ 86825 Israel; and D. Shtienberg, Department of Plant Pathology, the Volcani Center, A.R.O., Bet Dagan 50250 \\ Israel
}

\begin{abstract}
Edelstein, M., Cohen, R., Burger, Y., Shriber, S., Pivonia, S., and Shtienberg, D. 1999. Integrated management of sudden wilt in melons, caused by Monosporascus cannonballus, using grafting and reduced rates of methyl bromide. Plant Dis. 83:1142-1145.

Sudden wilt of melons induced by Monosporascus cannonballus is a worldwide problem, mainly in arid and semi-arid regions. Soil disinfestation by fumigation with methyl bromide is a common and very effective treatment for disease control. However, methyl bromide is expected to be banned from use within the next 5 to 10 years; therefore, alternative measures for disease management are urgently needed. In this study, the efficacy of methyl bromide at a reduced rate $\left(15 \mathrm{~g} / \mathrm{m}^{2}\right.$ instead of $\left.50 \mathrm{~g} / \mathrm{m}^{2}\right)$ and grafted plants, alone or in combination, was examined. Experiments were conducted in the "Arava region in southern Israel in naturally infested fields. First, various rootstock accessions were tested in three experiments. Of the eight rootstocks evaluated, cv. Brava (Cucurbita maxima) was selected to serve as a rootstock in the subsequent experiments due to its effects on wilt reduction (63 to 100\% reduction in two experiments and $35 \%$ reduction in one experiment) and its horticultural performance. Next, integration of grafting and a reduced rate of methyl bromide was tested in two experiments. The reduced methyl bromide rate suppressed disease, but results were variable (32 and $91 \%$ reduction in the two experiments). Grafting, when used alone, significantly reduced wilt incidence by 84 to $87 \%$ compared to untreated plots. Integration of the two control measures provided adequate and reliable results and wilt incidence was always significantly lower (75 to $100 \%$ reduction) than incidence in untreated plots. Because control by each measure alone varies, integrated application is preferable.
\end{abstract}

Additional keywords: fumigation, grafting, integrated pest management

Sudden wilt of melons (Cucumis melo), also known as melon collapse or vine decline, is a worldwide problem, mainly in arid and semi-arid regions (12). This disease is a major problem in the arid 'Arava region of southern Israel, which is the main out-of-season melon production area for the local market and for export. The sudden wilt syndrome is characterized by rapid wilt of plants bearing mature fruit and may result in total loss of the crop. Field trials and inoculation experiments conducted by Reuveni et al. in the early 1980s (15) showed that a Monosporascus sp., identified probably by mistake as $M$. eutypoides, was a primary agent of melon collapse in the Jordan Valley. Pathogenic-

Corresponding author: R. Cohen

E-mail: ronico@netvision.net.il

Contribution no. 150-99 from the Agricultural Research Organization, Newe Ya'ar Research Center, Agricultural Research Organization P.O.B. 1021, Ramat Yishay, Israel.

Accepted for publication 3 September 1999.

Publication no. D-1999-1020-01R

(C) 1999 The American Phytopathological Society ity tests performed in 1995 and 1996 (14) suggested that the most aggressive fungus involved in the sudden wilt syndrome of melons in the 'Arava Valley of southern Israel is $M$. cannonballus (1). M. cannonballus was reported to induce melon sudden wilt also in the southern United States, Central America, Japan, Tunisia, Saudi Arabia, and Spain $(2,6,11,12,17)$. Soil disinfestation by fumigation with methyl bromide is the common treatment used in the 'Arava to control this disease (18). However, methyl bromide is expected to be banned from use worldwide within the next 5 to 10 years (16), yet growing melons without methyl bromide is impossible. Therefore, alternative measures for disease management are urgently needed.

Melons and watermelons grafted on $\mathrm{Cu}$ curbita spp. rootstocks to combat diseases are common in various regions in the Mediterranean Basin and in southeastern Asia $(9,10)$. Grafted cucurbits are used mainly to overcome root diseases caused by Fusarium spp. (10). We found no data on the response of Cucurbita spp. used commercially as rootstocks to prevent $M$. cannonballus damage. Grafting is currently not used in Israel commercially, probably due to the current availability and high efficiency of methyl bromide. It is possible that grafted plants alone or integration of grafting with reduced rates of methyl bromide may suppress sudden wilt as effectively as a full rate of methyl bromide. Reduced rates of methyl bromide will be allowed in certain places during the phaseout period (16). In this study, various $\mathrm{Cu}$ curbita spp. were screened as a potential source of rootstock for grafting, and the efficacy of grafting and pre-plant fumigation of the soil with methyl bromide at reduced rates, solely and in combination, were studied.

\section{MATERIALS AND METHODS}

Grafting melon plants on Cucurbita sp. rootstocks. Seeds of melon (scion) and Cucurbita sp. (rootstocks; Table 1) were sown in seedlings trays (Polyvid, Mishmar HaNegev, Israel, $37 \mathrm{~mm} /$ cell, 128 cells/tray) filled with a $1: 1$ ( $\mathrm{vol} / \mathrm{vol}) \mathrm{mix}-$ ture of peat and vermiculite. The plants were grown in an environment-controlled greenhouse at 25 and $20^{\circ} \mathrm{C}$ day and night, respectively. Plants were grafted at the two-leaf stage. True leaves of the rootstocks were removed with a razor blade, creating a "V"-shaped cut between the rootstock's cotyledons, and an inverse "V"shaped cut was made on the stem of the scion, approximately $2 \mathrm{~cm}$ below the cotyledons, to fit the cut in the rootstock. Scion and rootstock were held with a grafting clip (Sakata Seed Corp. Yokohama, Japan). Grafted plants were transferred to a mist chamber $(>95 \%$ relative humidity) for 8 days, after which the relative humidity was reduced gradually for acclimatization.

Evaluation of rootstock response to sudden wilt. The response of eight rootstocks belonging to different species of Cucurbita (Table 1) to sudden wilt were evaluated in three field experiments, conducted in fields naturally infested with $M$. cannonballus (14). Of the eight rootstocks evaluated, only three ('TZ-148', 'Brava,' and 'Tetsukabuto') were tested in all three field experiments; the others were tested only once due to a limited number of seeds. The first two experiments were carried out in the autumn 1995, one at the Zohar Experiment Station at 'En Tamar (northern 'Arava) and the other in an organic field at 'En Yahav (Central 'Arava). Susceptible melon plants (cv. 'Arava, 
grafted and non-grafted) were transplanted on 12 September. Intra-row spacing was 50 $\mathrm{cm}$ and beds were $190 \mathrm{~cm}$ apart. Each experimental plot was $3.5 \mathrm{~m}$ long and consisted of seven transplants. There were four replicates per treatment (rootstocks) and the experiments were laid out in a randomized complete block design. The third experiment was conducted at 'En Yahav in the spring cropping season of 1996, on the same plot used for the autumn experiment. Melon plants were transplanted on 27 January. Plant spacing and the number of transplants per experimental plot were the same as for the autumn experiment, but there were only two replicate plots for each of the tested rootstocks.

Integrated management of sudden wilt. The efficacy of grafting and pre-plant fumigation with methyl bromide in suppression of sudden wilt was tested in two field experiments conducted at the Zohar Experiment Station. The first experiment was carried out in the 1997 spring cropping season (transplanted 23 January and harvested 26 April to 11 May). The second experiment was conducted in the 1997 autumn cropping season (transplanted 15 September and harvested 4 to 21 November). $\mathrm{Cv}$. 'Arava, which is highly susceptible to M. cannonballus, was used in each experiment. The spring experiment consisted of a factorial design with two main factors, (i) grafting (cv. 'Arava scions were either not grafted or were grafted on cv. Brava rootstock) and (ii) pre-planting treatment with methyl bromide. The second factor consisted of four levels: (i) untreated, (ii) methyl bromide which had been applied at a rate of $50 \mathrm{~g} / \mathrm{m}^{2}$ before the previous season (before the autumn cropping of 1996), (iii) methyl bromide applied at a reduced rate $\left(15 \mathrm{~g} / \mathrm{m}^{2}\right)$, and (iv) methyl bromide applied at the full rate $\left(50 \mathrm{~g} / \mathrm{m}^{2}\right)$. The autumn experiment consisted of a factorial design with two main factors: (i) grafting cv. 'Arava scions were either not grafted or were grafted on cv. Brava rootstock and (ii) pre-planting treatment with methyl bromide. The second factor consisted of three levels: (i) untreated, (ii) methyl bromide applied at a reduced rate $\left(15 \mathrm{~g} / \mathrm{m}^{2}\right)$, and (iii) methyl bromide. applied at the full rate $\left(50 \mathrm{~g} / \mathrm{m}^{2}\right)$.

Methyl bromide was applied via drip irrigation tubes, which were placed on beds prior to covering the beds with plastic sheets (Polyon, Barqay, Israel). Methyl bromide (Dead Sea Bromine Group, Be'er Sheva', Israel) was applied through the irrigation tubes at the desired rate ( 15 or 50 $\mathrm{g} / \mathrm{m}^{2}$ ) employing the hot gas method (8).

Disease assessments and yield quality measurements. All experiments were conducted in fields with a history of sudden wilt caused by M. cannonballus (14). Wilt was evaluated visually in each experiment at harvest. A plant was considered dead when the whole plant appeared irreversibly wilted. Involvement of $M$. cannonballus in wilting was confirmed by visual evaluation of perithecial development on wilted plant root samples after 3 weeks of incubation in paper bags at room temperature. The number of wilted plants and the total number of plants per plot were used to calculate the incidence of wilting (percent). Fruit were harvested twice a week upon ripening; there were four to six harvests in the different experiments. The fruit in each plot were counted and weighed. Total soluble solids (TSS, an indicator of fruit sugar content) was evaluated from a sample of five fruit per plot using an Atago digital refractometer. Samples (approximately $20 \mathrm{~g}$ ) were randomly taken from each fruit, manually squeezed, and the drops of juice were placed on the refractometer for analysis. Results were analyzed statistically by appropriate (oneor two-way) analysis of variance (ANOVA) tests. Data for disease incidence were transformed using arcsin function prior to analyses. When the $F$ values were significant at $p>0.05$, differences among the treatments were determined by Fisher's protected least significant difference (LSD) test.

\section{RESULTS}

Evaluation of rootstock response to sudden wilt. Wilt intensity in all three experiments was high and 89 to $100 \%$ of the non-grafted cv. 'Arava plants wilted by the end of the season (Table 1). The three rootstocks tested exhibited similar responses to the disease within each experiment with a significant reduction (68 to $100 \%$ ) in wilt incidence in the experiments conducted at 'En Tamar, but an insignificant reduction (4 to 35\%) in the 'En Yahav experiment (Table 1). Because the horticultural performance of the melons grafted on cv. Brava seemed to be better than that of the other transplant combinations, Brava was selected to serve as a rootstock in the subsequent experiments.

Integrated management of sudden wilt. Severe wilt developed in each experiment in untreated plants (94 to $100 \%$ wilt; Tables 2 and 3). The full rate of methyl bromide $\left(50 \mathrm{~g} / \mathrm{m}^{2}\right)$ was highly effective and sudden wilt was rare in this treatment. The reduced methyl bromide rate $\left(15 \mathrm{~g} / \mathrm{m}^{2}\right)$ was effective but results were variable (32\% control in the 1997 spring experiment and $91 \%$ control in the 1997 to 1998 autumn experiment). A previous-season methyl bromide treatment was highly effective as well (96\% control). Grafting, when employed as the sole control measure, significantly reduced wilt incidence by 84 and $87 \%$ in the two experiments. Integration of grafting and reduced rate of methyl bromide improved wilt suppression further in the fall but not in the spring experiment, when compared with each of the measures applied alone (Tables 2 and 3).

Effects on yield, yield components, and fruit quality. Yield was significantly affected by the sudden wilt disease, as reflected by the significant yield increase in treated plots. In the 'En Tamar spring 1997 experiment, for example, the yield in methyl bromide-treated plots with grafted plants were $5.7 \times$ higher than that in the untreated plots $\left(28.6\right.$ versus $0.51 \mathrm{~kg} / \mathrm{m}^{2}$, respectively; Table 2). Each of the control measures, when examined alone, resulted in a significant increase in yield $(P \leq 0.05)$ in comparison with untreated plots. When methyl bromide at the reduced rate and grafting were combined, yield was significantly higher as compared to each treatment applied alone (Table 2).

Table 1. Sudden wilt incidence (\%) caused by Monosporascus cannonballus in non-grafted and grafted melons (cv. 'Arava) on various rootstocks in three experiments ${ }^{y}$

\begin{tabular}{|c|c|c|c|c|c|}
\hline Rootstock cultivar & Rootstock species & Source of rootstock & $\begin{array}{c}\text { Ein Tamar } \\
\text { autumn } 1995^{z}\end{array}$ & $\begin{array}{c}\text { Ein Yahav } \\
\text { autumn } 1995^{z}\end{array}$ & $\begin{array}{c}\text { Ein Yahav } \\
\text { spring } 1996^{z}\end{array}$ \\
\hline Non grafted & Cucumis melo & Hazera, Israel & $93 \mathrm{a}$ & $100 \mathrm{a}$ & $89 \mathrm{a}$ \\
\hline $\mathrm{TZ}-148$ & Cucurbita maxima & Tezier, France & $10 \mathrm{~b}$ & $96 \mathrm{a}$ & $28 \mathrm{~b}$ \\
\hline Brava & Cucurbita maxima & Petoseed, United States & $0 \mathrm{~b}$ & $65 \mathrm{a}$ & $33 \mathrm{~b}$ \\
\hline Tetsukabuto & C. maxima $\times$ C. moschata & Takii Seed, Japan & $13 \mathrm{~b}$ & $65 \mathrm{a}$ & $50 \mathrm{~b}$ \\
\hline Marukanpyou & Lagenaria siceraria & Takii Seed, Japan & $76 \mathrm{a}$ & $\mathrm{nt}$ & $\mathrm{nt}$ \\
\hline Feggous & Cucumis melo & Inter Semences, Morocco & nt & $100 \mathrm{a}$ & nt \\
\hline Slaoui & Lagenaria siceraria & (Unknown) & $\mathrm{nt}$ & $100 \mathrm{a}$ & $\mathrm{nt}$ \\
\hline Just & Cucurbita sp. & Takii Seed, Japan & $14 \mathrm{~b}$ & $\mathrm{nt}$ & $\mathrm{nt}$ \\
\hline Butternut & Cucurbita moschata & Petoseed, United States & $67 \mathrm{a}$ & $\mathrm{nt}$ & $\mathrm{nt}$ \\
\hline
\end{tabular}

${ }^{y}$ Experiments were conducted in soil naturally infested at 'En Tamar (northern 'Arava) and at 'En Yahav (central 'Arava) in southern Israel. Disease incidence was evaluated 60 days after transplanting.

${ }^{\mathrm{z}}$ Within columns, values followed by the same letters, do not differ significantly $(P=0.05)$, as determined by Fisher's protected least significant difference test; $\mathrm{nt}=$ not tested. 
The number of fruit per unit area was the yield component affected most by the disease and increased by the treatments. In general, the effects of the different treatments on the number of fruit resembled their effects on yield. A large increase (up to 4.4×) was observed in the 1997 spring experiment with additive effects of methyl bromide and grafting; in the 1997 autumn experiment, only soil fumigation increased the number of fruit significantly. Fruit weight also was increased by the treatments significantly, but this increase was smaller (up to $1.3 \times$ ) than the increase in the number of fruit. Fruit quality (as measured by TSS) in the 1997 autumn experiment was not affected by the treatments (Table 3 ).

\section{DISCUSSION}

Growing grafted vegetables, including cucurbits, is a common method employed in Japan, Korea, the Mediterranean Basin, and some countries in Europe (10). The purpose of growing grafted melons is mainly to control Fusarium wilt caused by various races of $F$. oxysporum f. sp. melonis; to the best of our knowledge, no data are currently available on the possibility of using grafting against $M$. cannonballus.

Genetic sources for rootstocks resistant or tolerant to $M$. cannonballus may exist in various plants of the Cucurbitacea. Cucurbita, as a genus, was defined by Mertely et al. (13) as a host for M. cannonballus. Indeed, perithecia of $M$. cannonballus could be detected on various Cucurbita sp. roots recovered from the soil after harvest, although no wilt symptoms were evident throughout the growing season (S. Pivonia, unpublished). However, not much is known about the rate of infection of $\mathrm{Cu}$ curbita spp. compared with melons or other cucurbits and the response of different Cucurbita accessions to the pathogen.

In general, results obtained in this study suggest that grafting is an effective measure against melon sudden wilt. When cv. 'Arava scions were grafted on cv. Brava rootstocks, wilt incidence was significantly reduced (by 63 to 100\%) in four of the five experiments. However, in one experiment ('En Yahav, autumn 1995) where disease pressure was very high, wilt incidence in the grafted plants did not differ significantly (35\% reduction) from that in nongrafted plants. The variable performance of grafting is a known phenomenon (10). Moreover, a significant reduction in wilt incidence in a certain year does not necessarily reflect the whole picture. The pathogen population can still increase gradually in the soil and, once it reaches a certain level, grafted plants might be endangered and provide limited control. In addition, differences in environmental conditions, especially high temperatures, can enhance symptom development $(3,7)$ and cause disease in grafted plants. The differences in the response to the disease of grafted plants in the autumn of 1995 at 'En Yahav versus 'En Tamar is an example of one such possible variation. Thus, occasional incidence of wilt should be expected and additional measures for disease control should be implemented.

Table 2. Effects of methyl bromide and grafting on sudden wilt incidence, yield and yield components, in an experiment conducted at Ein Tamar in spring $1997^{\mathrm{w}}$

\begin{tabular}{|c|c|c|c|c|c|}
\hline Soil, analysis & Grafting, variables $^{x}$ & Wilt incidence $(\%)$ & Marketable fruit (no./m²) & Fruit wt. (kg) & Yield $\left(\mathrm{kg} / \mathrm{m}^{2}\right)$ \\
\hline \multirow[t]{2}{*}{ Untreated } & - & 100 & 0.82 & 0.61 & 0.51 \\
\hline & + & 16 & 2.57 & 0.71 & 1.82 \\
\hline \multicolumn{6}{|l|}{ Methyl bromide } \\
\hline \multirow[t]{2}{*}{ Previous season } & - & 4 & 2.62 & 0.65 & 1.70 \\
\hline & + & 2 & 3.46 & 0.77 & 2.66 \\
\hline \multirow{2}{*}{$15 \mathrm{~g} / \mathrm{m}^{2}$} & - & 68 & 2.01 & 0.66 & 1.33 \\
\hline & + & 25 & 3.57 & 0.79 & 2.82 \\
\hline \multirow[t]{2}{*}{$50 \mathrm{~g} / \mathrm{m}^{2}$} & - & 2 & 2.89 & 0.69 & 1.99 \\
\hline & + & 0 & 3.62 & 0.79 & 2.86 \\
\hline \multicolumn{6}{|l|}{ ANOVAy } \\
\hline \multirow[t]{2}{*}{ Main effects } & $\mathrm{S}$ & 0.0001 & 0.0225 & 0.0004 & 0.0001 \\
\hline & G & 0.0001 & 0.0042 & 0.0001 & 0.0001 \\
\hline Interaction & $\mathrm{S} \times \mathrm{G}$ & 0.0001 & 0.7738 & 0.3970 & 0.8476 \\
\hline $\mathrm{LSD}^{z}$ & $\ldots$ & 17.4 & 0.7747 & 0.08 & 4.93 \\
\hline
\end{tabular}

${ }^{w}$ Melon (cv. 'Arava) transplants were grown in soil naturally infested with Monosporascus cannonballus. Methyl bromide at the commercial rate (50 $\mathrm{g} / \mathrm{m}^{2}$ ) was applied before the autumn cropping season of 1996.

${ }^{x}$ No graft $(-)$ or graft $(+) ; \mathrm{S}=$ soil and $\mathrm{G}=$ grafting.

${ }^{\mathrm{y}} \mathrm{ANOVA}=$ analysis of variance $(P$ values $)$

${ }^{\mathrm{z}} \mathrm{LSD}=$ least significant difference.

Table 3. Effects of methyl bromide and grafting on Monosporascus wilt, yield, yield components, and fruit quality in an experiment conducted at Ein Tamar in autumn $1997^{\mathrm{v}}$

\begin{tabular}{|c|c|c|c|c|c|c|}
\hline Soil, analysis & Grafting, variables $^{w}$ & Wilt incidence (\%) & Marketable fruits $\left(\mathrm{no.} / \mathrm{m}^{2}\right)$ & Fruit wt. (kg) & Yield $\left(\mathrm{kg} / \mathrm{m}^{2}\right)$ & $\operatorname{TSS}(\%)^{x}$ \\
\hline \multirow[t]{2}{*}{ Untreated } & - & 94 & 1.40 & 1.00 & 1.40 & 10.2 \\
\hline & + & 12 & 1.79 & 1.23 & 2.20 & 11.6 \\
\hline \multicolumn{7}{|l|}{ Methyl bromide } \\
\hline \multirow[t]{2}{*}{$15 \mathrm{~g} / \mathrm{m}^{2}$} & - & 8 & 2.47 & 1.06 & 2.61 & 11.7 \\
\hline & + & 0 & 2.29 & 1.19 & 2.73 & 10.3 \\
\hline \multirow[t]{2}{*}{$50 \mathrm{~g} / \mathrm{m}^{2}$} & - & 7 & 2.39 & 1.07 & 2.56 & 11.3 \\
\hline & + & 0 & 2.44 & 1.08 & 2.63 & 11.5 \\
\hline \multicolumn{7}{|l|}{ ANOVA $^{\mathrm{y}}$} \\
\hline \multirow[t]{2}{*}{ Main effects } & $\mathrm{S}$ & 0.0001 & 0.0001 & 0.7142 & 0.0059 & 0.3317 \\
\hline & G & 0.0001 & 0.6443 & 0.0380 & 0.1360 & 0.5729 \\
\hline Interaction & $\mathrm{S} \times \mathrm{G}$ & 0.0001 & 0.3801 & 0.2981 & 0.2469 & 0.1083 \\
\hline $\mathrm{LSD}^{\mathrm{z}}$ & $\ldots$ & 10.3 & 0.18 & 0.18 & 0.76 & 2.1 \\
\hline
\end{tabular}

${ }^{\mathrm{v}}$ Melon (cv. 'Arava) transplants were grown in soil naturally infested with Monosporascus cannonballus.

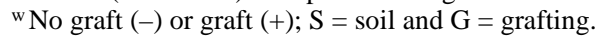

${ }^{x}$ TSS $=$ total soluble solids

y ANOVA $=$ analysis of variance.

${ }^{\mathrm{z}} \mathrm{LSD}=$ least significant difference. 
Effects of the treatments on yield resemble those obtained on wilt suppression. In general, treatments that resulted in reduced wilt also significantly increased yield. The main yield component that was affected by the disease (and thus was increased by the control treatments) was the number of fruit per unit area. Fruit quality (tested on marketable fruit only), which is determined mostly by its TSS, was not affected. These results reflect the expression of the epidemic of the disease in the field, where infected plants collapse shortly before harvest and do not produce any marketable fruit.

Part of the yield increase observed following soil fumigation with methyl bromide and the use of grafted plants is attributed to disease control. However, increased growth response, which is not related to the control of a major pathogen, is a wellknown phenomenon in both soil-fumigation and grafted plants (10). The increased growth response effect following soil fumigation results largely from the decrease in, or elimination of, minor pathogens (5). In grafted plants, the rootstock's vigorous root system is often capable of absorbing water and nutrients more efficiently compared to the non-grafted plant, and may serve as a good supplier of endogenous plant hormones (5). However, the rootstock effect varies greatly with scion cultivar and growing season (10). An increased growth response effect may have been more pronounced in the 1997 spring experiment, when wilt incidence in the grafted and nongrafted plants treated with two of the methyl bromide treatments (previous season, and full rate methyl bromide) was similar (0 to $4 \%$ wilt). However, yield in the grafted plants was significantly higher (by 0.87 to $0.98 \mathrm{~kg} / \mathrm{m}^{2}$ ) than in the non-grafted plants. This effect was not apparent, however, in the 1997 autumn experiment.

Grafted plants are expected to be expensive. Seeds of both rootstock and scion may be expensive hybrids. The preparation of the transplant includes manual labor and expensive post-grafting handling $(9,10)$. Extensive efforts to overcome the labor problem are being made in Japan, where private companies, institutions, and universities are attempting to develop feasible grafting robots. In the near future, it may be common practice for growers to buy seedlings grafted by robot (9).

In this study integration of two control measures was tested: grafting and preplanting treatments with methyl bromide at reduced rate. Integration of the two control measures provided an adequate and reliable solution to sudden wilt of melon. Wilt incidence in plots treated with both measures was always significantly lower (by 75 to $100 \%$ ) than that in untreated plots. Yield in these plots was always similar to (or even higher than) yield in the plots treated with full rate methyl bromide. The overall conclusion is that reduced rates of methyl bromide and grafting can be used as alternative measures to full-rate application of methyl bromide. Furthermore, post-planting application of the fungicide fluazinam, which was found effective against Monosporascus sudden wilt (4), may be combined as well.

\section{LITERATURE CITED}

1. Alcantara, T. P., Rasmmussen, S. I., And Stanghellini, M. E. 1997. Biological characterization of Monosporascus cannonballus. (Abstr.) Phytopathology 87:S3 .

2. Bruton, B. D. 1997. Occurrence of vine decline disease on muskmelon in Guatemala. Plant Dis. 81:694.

3. Cohen, R., Elkind, Y., Burger, Y., Offenbach, R., and Nerson, H. 1996. Variation in the response of melon genotypes to sudden wilt. Euphytica 87:91-95.

4. Cohen, R., Pivonia, S., Shtienberg, D., Raz, D., Shraiber, S., Gerstl, Z., and Katan, J. 1997. Chemical control of Monosporascus, the causal agent of the root rot and vine decline disease of melons. (Abstr.) Phytoparasitica 25:255.

5. Cook, R. J., and Baker, K. F. 1983. The Na- ture and Practice of Biological Control of Plant Pathogens. The American Phytopathological Society, St. Paul, MN.

6. Karlatti, R. S., Abdeen, F. M., and Al-Fehaid, M. S. 1997. First report of Monosporascus cannonballus on melons in Saudi Arabia. Plant Dis. 81:1215.

7. Kim, D. H., Rasmussen, S. L., and Stanghellini, M. E. 1995. Monosporascus cannonballus root rot of muskmelon: Root infection and symptoms development in relation to soil temperature. (Abstr.) Phytopathology 85:1195.

8. Klein, L. 1996. Methyl bromide as soil fumigant. Pages 191-235 in: The Methyl Bromide Issue. C. H. Be, N. Price, and B. Chakrabarti, eds. John Wiley \& Sons, New York.

9. Kurata, K. 1994. Cultivation of grafted vegetables II. Development of grafting robots in Japan. HortScience 29:240-244.

10. Lee, J. M. 1994. Cultivation of grafted vegetables I. Current status, grafting methods, and benefits. HortScience 29:235-239.

11. Martyn, R. D., Lovic, B. R., Maddox, D. A., Germash, A., and Miller, M. E. 1994. First report of Monosporascus root rot/vine decline of watermelon in Tunisia. Plant Dis. 78:1220.

12. Martyn, R. D., and Miller, M. E. 1996. Monosporascus root rot and vine decline, an emerging disease of melons worldwide. Plant Dis. 80:716-725.

13. Mertely, J. C., Martyn, R. D., Miller, M. E., and Bruton, B. D. 1993. An expanded host range for the muskmelon pathogen Monosporascus cannonballus. Plant Dis. 77:667-673.

14. Pivonia, S., Cohen, R., Kafkafi, U., BenZe'ev, I. S., and Katan, J. 1997. Sudden wilt of melons in southern Israel: Fungal agents and relationship with plant development. Plant Dis. 81:1264-1268.

15. Reuveni, R., Krikun, J., and Shani, U. 1983. The role of Monosporascus eutypoides in a collapse of melon plants in arid area of Israel. Phytopathology 73:1223-1226.

16. Ristaino, J. B., and Thomas, W. 1997. Agriculture, methyl bromide and the ozone hole, can we fill the gap? Plant Dis. 81:964-977.

17. Stanghellini, M. E., Kim, D. H., and Rasmussen, S. L. 1996. Ascospores of Monosporascus cannonballus: Germination and distribution on cultivated and desert soils in Arizona. Phytopathology 86:509-514.

18. Ucko, O., Maduel, A., Grinstein, A., and Katan, J. 1992. Combined methods of soil disinfestation for controlling melon collapse with reduced methyl bromide dosages. (Abstr.) Phytoparasitica 20:229-230. 